\title{
Demographic and Ecological Survey of Dog Population in Aba, Abia State, Nigeria
}

\author{
Gbeminiyi Richard Otolorin, Jarlath U. Umoh, and Asabe Adamu Dzikwi \\ Department of Veterinary Public Health and Preventive Medicine, Faculty of Veterinary Medicine, \\ Ahmadu Bello University, Zaria, Kaduna State, Nigeria
}

Correspondence should be addressed to Gbeminiyi Richard Otolorin; drniyiotolorin@yahoo.com

Received 19 February 2014; Accepted 20 March 2014; Published 9 April 2014

Academic Editors: R. Klopfleisch, S. Whisnant, and W. Yang

Copyright (C) 2014 Gbeminiyi Richard Otolorin et al. This is an open access article distributed under the Creative Commons Attribution License, which permits unrestricted use, distribution, and reproduction in any medium, provided the original work is properly cited.

\begin{abstract}
Dog ecology is essential in understanding the distribution, structure, and population density of dogs and pattern of dog ownership in any given area. A cross-sectional study was designed to study dog ecology in Aba, Abia state, Nigeria, from April to June 2013. The study revealed that the 500 households surveyed possessed 5,823 individuals and 747 dogs, giving a dog to human ratio of 1:7.8; hence dog population in Aba was estimated to be 68,121. About 495/747 (66.3\%) of the dogs were exotic and 465/747 (62.2\%) were males. A total of 319/500 (63.8\%) of the households had fences that restrained dog movement and there was no incidence of dog bite in $447 / 500(89.4 \%)$ of the households surveyed. There were statistical associations between vaccination against antirabies and breeds of dogs $\left(\chi^{2}=79.8, \mathrm{df}=2, P<0.005\right)$. Exotic breed (adjusted $\left.\mathrm{OR}=0.39 ; \mathrm{CI}=0.23-0.65\right)$ and local breed of dogs (adjusted $\mathrm{OR}=0.08 ; \mathrm{CI}=0.04-0.14)$ had less odds of being vaccinated as compared to crossbreed of dogs. About 126 dogs $(2.5$ dogs per street) were estimated from street counts survey. The relative high dog to human ratio and low vaccination coverage of owned dogs population pose public health concerns requiring adequate public health education and proper antirabies vaccination coverage of dogs in the study area.
\end{abstract}

\section{Introduction}

Dog ecology involves studies on dog population density, dog population structure, and pattern of dog ownership [1]. In nearly all parts of the world, dogs pose serious human health, socioeconomic, political, and animal welfare problems [2]. In developing countries, the domestic dog is the most important reservoir and vector of human rabies, accounting for $99 \%$ of exposures (WHO, 1992). Rates of disease transmission depend on the density of the dog population and social behaviour that determines the extent of contact [3]. As recognised by World Health Organization [4] dog demography studies are key to addressing many of these knowledge gaps even more so as rapid changes in human and dog demographics have important implications for the dynamics and control of rabies [5].

Rabies epidemiology in the dog reservoir is directly associated with dog ecology; thus, better understanding of dog ecology would be useful for designing appropriate rabies control measures in the dog population [6]. The dog: human ratio most commonly lies between $1: 6$ and $1: 10$, but considerable variation exists [7]. Urban areas in Africa have a ratio of $1: 21.2$, while rural areas in Africa have a ratio of $1: 7.4$ [8]. The ratio of owned dogs to people is usually higher in rural areas of a country, but there is also considerable variation within cities [9]. The structure and turnover of a dog population are determined by a great number of different factors. Its analysis depends on vital statistics such as sex and age ratios, natality and rearing success, and survival and mortality rates [10]. Some dog population densities studies in Nigeria have been carried out applying techniques such as total street-dog count and estimates from the rate of capture and recapture [11-14]. This research aims to determine the distribution, structure, and population density of dogs and the pattern of dog ownership (dog ecology) in Aba, Abia state, Nigeria. 


\section{Materials and Methods}

2.1. Study Area. The study was carried out in Aba, Abia state, located in Southeastern Nigeria, consisting of two local government areas, Aba North and Aba South. Aba is a major urban settlement and commercial centre in a region that is surrounded by small villages and towns. Aba is well known for its industrial nature, manufacturing industries, and large scale trading. Aba lies between latitudes $5^{\circ} 07^{\prime} \mathrm{N}$ and between longitudes $7^{\circ} 22^{\prime} \mathrm{E}$. With a temperature of about $21^{\circ} \mathrm{C}$, the climate is humid tropical type and is characterized by wet and dry seasons [15].

2.2. Study Design. A cross-sectional study was carried out to evaluate dog ecology in Aba, Abia state, between April and June 2013 in Aba North and Aba South local government areas (LGAs).

2.3. Survey Methods. Fifty (50) streets in the study area consisting of twenty-five (25) streets each in Aba North and Aba South LGAs were surveyed using compound questionnaire survey and street counts. A total of 500 households, 250 each in Aba North and Aba South local government area, were surveyed.

2.3.1. Compound Questionnaire Survey of Dogs. Starting from the 1st major street of each local government area, every 5th street was surveyed using systematic random sampling technique. In each chosen street, starting from the 1st houses on either side, every 10th house was selected, and an adult member on either side was interviewed using questionnaire. Information obtained included household information such as numbers of dogs in the premises, housing and control of dog movement, and history of dog bites and individual dog information such as breed, sex, age, source of dog, source of food, and vaccination status. A total of ten (10) houses were surveyed in each street chosen. Houses without dogs or houses that refused to participate in the compound questionnaire survey were skipped for the next house possessing $\operatorname{dog}(s)$.

2.3.2. Street Counts. Dogs on the street were counted using the photographic recapture technique (Beck's method). The area surveyed in Aba North and Aba South LGAs was divided into 4 areas determined by the major roads (Faulks road in Aba North, Okigwe road in Aba North, Asa road Aba south in Aba South, and Port harcourt road in Aba South) linking the streets. It involved two street counts on two different days and the counts were averaged to reduce sampling error. On each day of the study, the counting of dogs was carried out early in the morning (between 6 and 9 am) and in the evening (5.30 to $7.00 \mathrm{pm})$. Every dog within a given distance was photographed and recorded. The number of dogs counted in the selected streets in each area was estimated using the following formula:

$$
N=\frac{\sum(M n)}{\sum m},
$$

TABLE 1: Household information on dog ecology obtained from respondents in 500 households in Aba North and Aba South LGA of Abia state (from April to June 2013).

\begin{tabular}{|c|c|c|}
\hline Variable & Frequency & $\begin{array}{c}\text { Percentage } \\
(\%)\end{array}$ \\
\hline \multicolumn{3}{|l|}{ Enclosure of home } \\
\hline No fence & 66 & 13.2 \\
\hline Fence/wall, but does not restrain dogs & 115 & 23.0 \\
\hline Fence/wall, completely restrain dogs & 319 & 63.8 \\
\hline \multicolumn{3}{|l|}{ Housing of dogs } \\
\hline Specially constructed house/cage & 368 & 73.6 \\
\hline On house passage way/corridor & 105 & 21.0 \\
\hline Anywhere on the premises & 27 & 5.4 \\
\hline \multicolumn{3}{|l|}{ Control of $\operatorname{dog}(\mathrm{s})$ movement } \\
\hline Never allowed to leave premises & 464 & 92.8 \\
\hline Allow to roam freely & 36 & 7.2 \\
\hline \multicolumn{3}{|l|}{ Do you observe stray dogs on your street } \\
\hline Yes & 112 & 22.4 \\
\hline No & 388 & 77.6 \\
\hline \multicolumn{3}{|l|}{$\begin{array}{l}\text { Has any member of the household been } \\
\text { bitten by stray dog in the last } 12 \text { months }\end{array}$} \\
\hline Yes & 63 & 12.6 \\
\hline No & 437 & 87.4 \\
\hline \multicolumn{3}{|l|}{$\begin{array}{l}\text { Do dogs other than yours eat at your } \\
\text { home }\end{array}$} \\
\hline Yes & 29 & 5.8 \\
\hline No & 471 & 94.2 \\
\hline Total & 500 & 100 \\
\hline
\end{tabular}

where $M=$ the number of dogs photographed each time and considered "marked", that is, "observed"; $m=$ the number of dogs recognised as being previously photographed, that is, "reobserved"; $\sum m=$ the summation of $m$ to that point in time; $n=$ the total number of dogs previously observed; that is, each day's observations $(M)$ less than those previously observed $(m)$ would be added to each day; $M n=$ the product of each days $M$ and $n ; \sum(M n)=$ the summation of $M n$ to that point in time; and $N=$ the population estimate [10].

2.4. Data Analysis. In this study, data generated was analysed using the statistical packages for social sciences (SPSS) Version 17.0. Data obtained was presented using tables and charts. Chi-square test was used where appropriate to test for association of variables obtained from the questionnaires. Values of $P<0.05$ were considered significant. Odds ratio and adjusted odds ratio using multivariable logistic regression analysis were also utilized.

\section{Results}

In the 500 households surveyed $63.8 \%$ had fences/walls that completely restrained dogs movement and 23\% households had fences that do not restrain dogs movement, while $13.2 \%$ of the households had no fence. Most of the households (73.6\%) 
TABLE 2: Information obtained from 500 dog owning households in Aba North and Aba South LGA of Abia state (from April to June 2013).

\begin{tabular}{|c|c|c|}
\hline Variable & Frequency & Percentage $(\%)$ \\
\hline \multicolumn{3}{|l|}{ Breeds of dogs } \\
\hline Exotic & 495 & 66.3 \\
\hline Local & 142 & 19.0 \\
\hline Cross & 110 & 14.7 \\
\hline \multicolumn{3}{|l|}{ Sex of dogs } \\
\hline Male & 465 & 62.2 \\
\hline Female & 282 & 37.8 \\
\hline \multicolumn{3}{|l|}{ Ages of dogs } \\
\hline $0-6$ month & 284 & 38.0 \\
\hline $7-12$ month & 169 & 22.6 \\
\hline$>12$ month & 294 & 39.4 \\
\hline \multicolumn{3}{|l|}{ Source of dogs } \\
\hline From own bitch & 367 & 49.1 \\
\hline Bought & 334 & 44.7 \\
\hline Received as gift & 46 & 6.2 \\
\hline \multicolumn{3}{|l|}{ Reason for dog ownership } \\
\hline Guard dogs & 474 & 63.5 \\
\hline Sale/breeding & 182 & 24.4 \\
\hline Pet & 91 & 12.2 \\
\hline \multicolumn{3}{|l|}{ Confinement of dogs } \\
\hline Day & 438 & 58.6 \\
\hline Night & 13 & 1.7 \\
\hline Day and night & 260 & 34.8 \\
\hline Allow to roam & 36 & 4.8 \\
\hline \multicolumn{3}{|l|}{ Feeding of dogs } \\
\hline Household members & 649 & 86.9 \\
\hline Neighbours & 1 & 0.1 \\
\hline Find its own food & 3 & 0.4 \\
\hline Neighbours/household & 94 & 12.6 \\
\hline \multicolumn{3}{|l|}{ Rabies vaccination status } \\
\hline Yes & 298 & 39.9 \\
\hline No & 324 & 43.4 \\
\hline Not up to vaccination age & 125 & 16.7 \\
\hline Total & 747 & 100 \\
\hline
\end{tabular}

had specially constructed houses/cages as housing for their dogs, while $5.4 \%$ indicated their dogs were kept anywhere on the premises. About $92.8 \%$ of the households never allowed their dogs to leave their premises, while $7.2 \%$ allow their dogs to roam freely in the neighbourhood (Table 1).

A total of 747 dogs were present in the 500 households surveyed. Majority of the dogs (66.3\%) were exotic, $19 \%$ were local, and $14.7 \%$ were crossbreeds. Most of the dogs (62.2\%) were males, while females were $37.8 \%$ of the total number of dogs. A total of $38.0 \%$ of the dogs were within 0 to 6 months of age and $39.4 \%$ greater than 12 months of age. During the day $58.6 \%$ of the dogs were confined to restrict their movement, while $1.7 \%$ of the dogs were confined during the night. A total of $47.9 \%$ of the dogs were vaccinated against rabies; only dogs that had attained the age of vaccination against rabies were
TABLE 3: Structure of dogs and human population in compound count carried out in Aba North and Aba South LGA.

\begin{tabular}{lc}
\hline Variables & Values \\
\hline Number of compounds surveyed & 500 \\
Total number of people in the streets surveyed & $\mathbf{5 8 2 3}$ \\
Total number of dogs & $\mathbf{7 4 7}$ \\
Dog human ratio & $1: 7.8$ \\
Average number of dogs per house & 1.5 \\
Total dog population size estimated from street count & $\mathbf{1 2 6}$ \\
2006 population census of Aba North and Aba South & 531,340 \\
LGA & \\
Estimated dog population in Aba North and Aba South & 68,121 \\
LGA & \\
\hline
\end{tabular}

considered in estimating the antirabies vaccination coverage in the 500 households surveyed (Table 2).

Among the 500 households surveyed there were 5,823 occupants and 747 dogs. The average number of dogs per each house surveyed was 1.5 , while the dog to human ratio was $1: 7.8$. The street count of dogs was 126 dogs ( 67 dogs in Aba North and 59 dogs in Aba South). From the 2006 population census figure of Aba North and Aba South which is estimated as 531, 340 people the estimated dog population in Aba North and Aba South is about 68,121 (Table 3).

Chi-square analysis was used to determine association between dog vaccination status and various pieces of individual dog information. There were associations between breeds of dogs $\left(\chi^{2}=79.8, \mathrm{df}=2, P<0.005\right)$, age of dogs $\left(\chi^{2}=22.9\right.$, $d f=2, P<0.005)$, reason for $\operatorname{dog}$ ownership $\left(\chi^{2}=8.1, \mathrm{df}=\right.$ $2, P<0.005)$, confinement of $\operatorname{dogs}\left(\chi^{2}=10.0, \mathrm{df}=3, P<\right.$ 0.005 ), and rabies vaccination status of dog. These variables were further analysed using multivariable logistic regression analysis; exotic breed (adjusted $\mathrm{OR}=0.39 ; \mathrm{CI}=0.23-0.65$ ) and local breed of dogs (adjusted OR $=0.08 ; \mathrm{CI}=0.04-0.14$ ) had less odds of being vaccinated as compared to crossbreeds. Similarly dogs used as guard dogs (adjusted OR $=0.65$; CI $=0.37-1.12$ ) and dogs used for breeding/sale (adjusted OR $=0.41 ; \mathrm{CI}=0.22-0.79)$ purposes had less odds of being vaccinated as compared to dogs used as pets (Table 4).

\section{Discussion}

Information obtained from 500 households surveyed indicates a relative high density of dogs in the study area (dog to human ratio of $1: 7.8$ ) probably due to the absence of religious and cultural inhibition to the keeping of dogs in Aba, Abia state. This is in contrast to the low density of dogs in other urban cities in Nigeria, where dog to human ratio is $1: 43$ in Makurdi, Benue state [16], 1:21 in Lagos, Lagos state, and $1: 1000$ in the moslem dominated part of Kaduna North, Kaduna state [7].

Most of the houses had fences that completely restrain dog movement as the survey was conducted in an urban area where most houses are properly demarcated from each other by well defined fences. Majority of the households had specially constructed houses/cages for their dogs and 
TABLE 4: Chi-square and multivariable logistic regression analysis of vaccination status with individual dog information in Aba, Abia state.

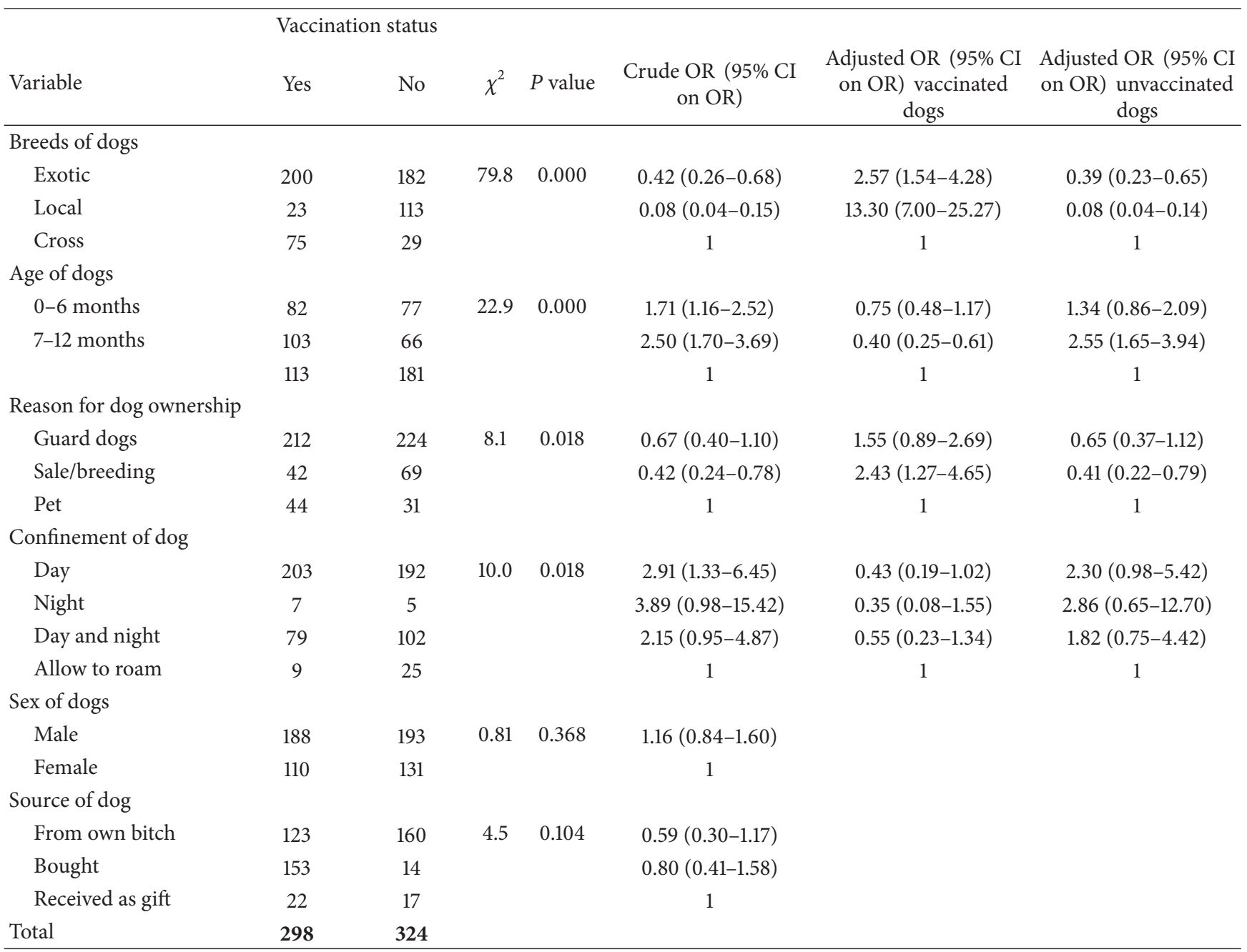

never allowed their dogs to leave the household premises. Dogs owned by inhabitants of the town are mostly exotic breed; hence they are well cared for because of the value attached to these dogs. Most of the respondents interviewed indicated low activity of free roaming dogs in their streets, with majority of the households reporting that no stray dogs eat in their homes. This is further confirmed by the result of the street count where few dogs (126) were seen in the 50 streets surveyed in the study area. Hence nuisances caused by free roaming dogs pose little problem in the area.

The antirabies vaccination coverage of dogs in the houses surveyed was estimated at $47.9 \%$. This still falls below the World Health Organization standard of vaccination of 70$80 \%$ dog population in an area to boost herd immunity [17]. This vaccination rate can be further improved if there are more veterinary clinics in the city and dog owners who are mainly traders create time out of their busy schedules to give their dogs the required veterinary care. Local breed of dogs was the least vaccinated against rabies due to the low priority given to this breed by most owners as compared with exotic and crossbreeds. Dogs within 7-12-months-old had higher antirabies vaccination frequency; this may be because dog owners see dogs at this age category as more likely to be aggressive and likely to be involved in dog bites; also more male dogs were kept than female dogs as they are perceived as better guard dogs than the females and are hence kept for security purposes.

\section{Conclusion}

The study revealed that the relatively high dog to human ratio and the vaccination coverage which falls below the recommended WHO standard pose public health concerns and require proper and well planned intervention aimed at adequate public health education and adequate antirabies vaccination coverage of dogs in the study area. Also dog ecology survey was able to determine that 500 households possess an average of 1.5 dogs per household with an estimated dog population in Aba being 68,121. This information is very important and can serve as a guide in the planning of antirabies campaign programme in Aba, Abia state. 


\section{Conflict of Interests}

The authors declare that there is no conflict of interests regarding the publication of this paper.

\section{References}

[1] S. Cleaveland, M. Kaare, D. Knobel, and M. K. Laurenson, "Canine vaccination-providing broader benefits for disease control," Veterinary Microbiology, vol. 117, no. 1, pp. 43-50, 2006.

[2] M. Ratsitorahina, J. H. Rasambainarivo, S. Raharimanana et al., "Dog ecology and demography in Antananarivo, 2007," BMC Veterinary Research, vol. 5, article 21, 2009.

[3] World Health Organization, Report of the WHO Expert Committee on Rabies, WHO Technical Report Series, no. 824, World Health Organization, Geneva, Switzerland, 1992.

[4] WHO, Report of WHO Consultation on Dog Ecology Studies Related to Rabies Control, World Health Organization, Geneva, Switzerland, 1st edition, 1988.

[5] K. Hampson, J. Dushoff, S. Cleaveland et al., "Transmission dynamics and prospects for the elimination of canine Rabies," PLoS Biology, vol. 7, no. 3, pp. 0462-0471, 2009.

[6] H. C. Matter and T. J. Daniel, "Dog ecology and population biology," in Dogs, Zoonoses and Public Health, C. N. L. Macpherson, F. X. Meslin, and A. I. Wandeler, Eds., pp. 17-62, CABI Publishing, New York, NY, USA, 2000.

[7] S. I. Oboegbulem and I. E. Nwakonobi, "Population density and ecology of dogs in Nigeria: a pilot study," Revue Scientifique et Technique de Office International des Epizooties, vol. 8, pp. 733745, 1989.

[8] D. L. Knobel, S. Cleaveland, P. G. Coleman et al., "Re-evaluating the burden of rabies in Africa and Asia," Bulletin of the World Health Organization, vol. 83, no. 5, pp. 360-368, 2005.

[9] T. Lembo, K. Hampson, M. T. Kaare et al., "The feasibility of canine rabies elimination in Africa: dispelling doubts with data," PLoS Neglected Tropical Diseases, vol. 4, no. 2, article e626, 2010.

[10] WHO/WSPA, Guidelines for Dog Population Management. World Health Organisation/World Society for the Protection of Animals, WHO/ZOON/90.165, World Health Organization, Geneva, Switzerland, 1990.

[11] P. M. Akombo, Dog ecology and epidemiological studies of canine rabies in Benue State, Nigeria [M.S. thesis], Ahmadu Bello University, Zaria, Nigeria, 2009.

[12] A. D. El-Yuguda, A. A. Baba, and S. S. A. Baba, "Dog population structure and cases of rabies among dog bite victims in urban and rural areas of Borno State, Nigeria," Tropical Veterinarian, vol. 25, pp. 34-40, 2007.

[13] A. E. J. Okoh, Dog ecology with reference to surveillance of rabies and characterisation of rabies virus in Plateau state, Nigeria [Ph.D. thesis], Ahmadu Bello University, Zaria, Nigeria, 1986.

[14] E. O. Ezeokoli and J. U. Umoh, "Dog population studies," Zariya Veterinarian, vol. 1, pp. 27-30, 1986.

[15] Abia State Government, 2012, http://www.abiastate.gov.ng/.

[16] E. A. Omudu, E. O. Otache, and S. M. Adelusi, "Studies on dog population in Makurdi, Nigeria," Journal of Research in Forestry, Wildife and Environment, vol. 2, pp. 185-93, 2010.

[17] World Health Organization, WHO Expert Consultation on Rabies: First Report, WHO Technical Report Series 931, World Health Organization, Geneva, Switzerland, 2004. 

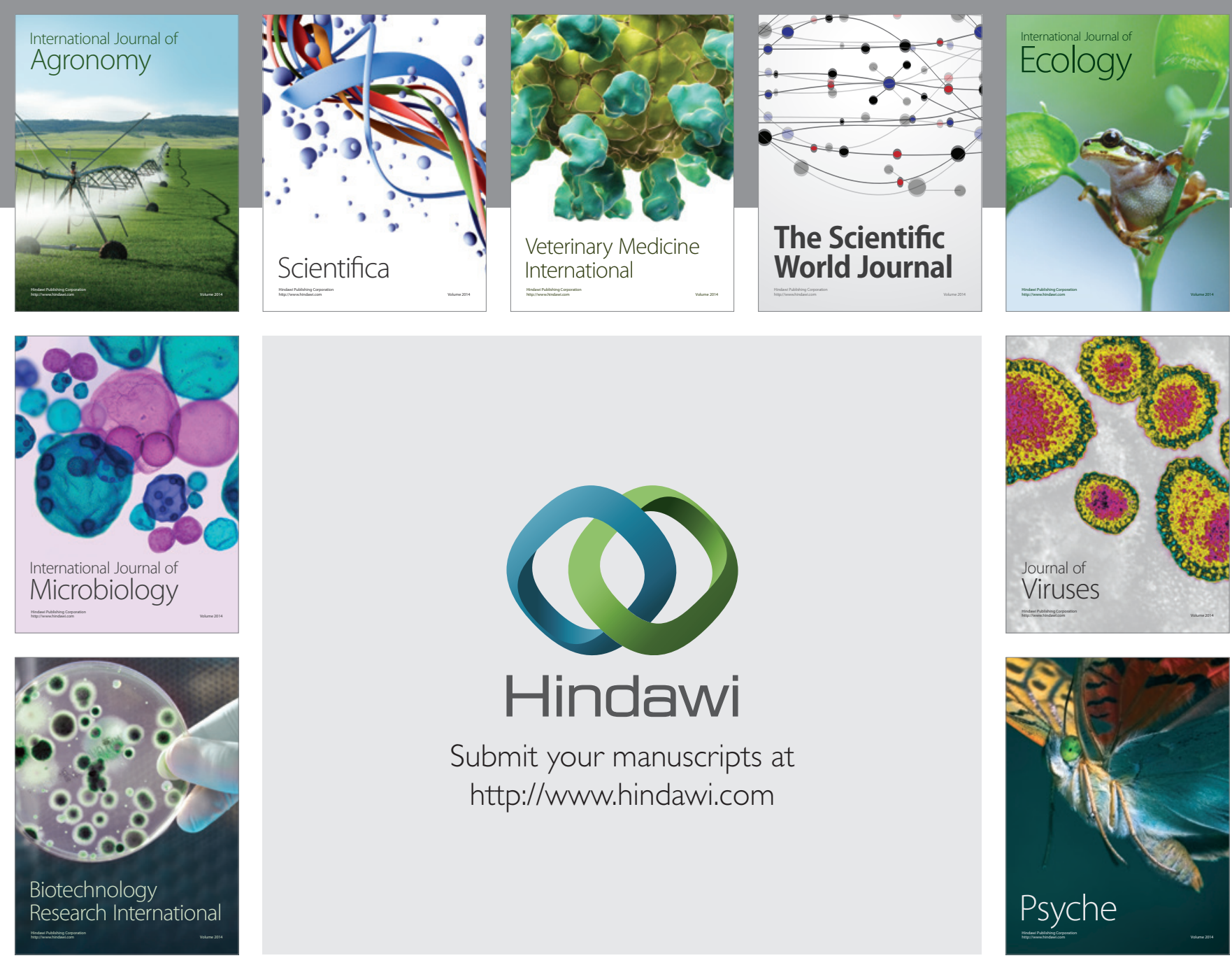

Submit your manuscripts at http://www.hindawi.com
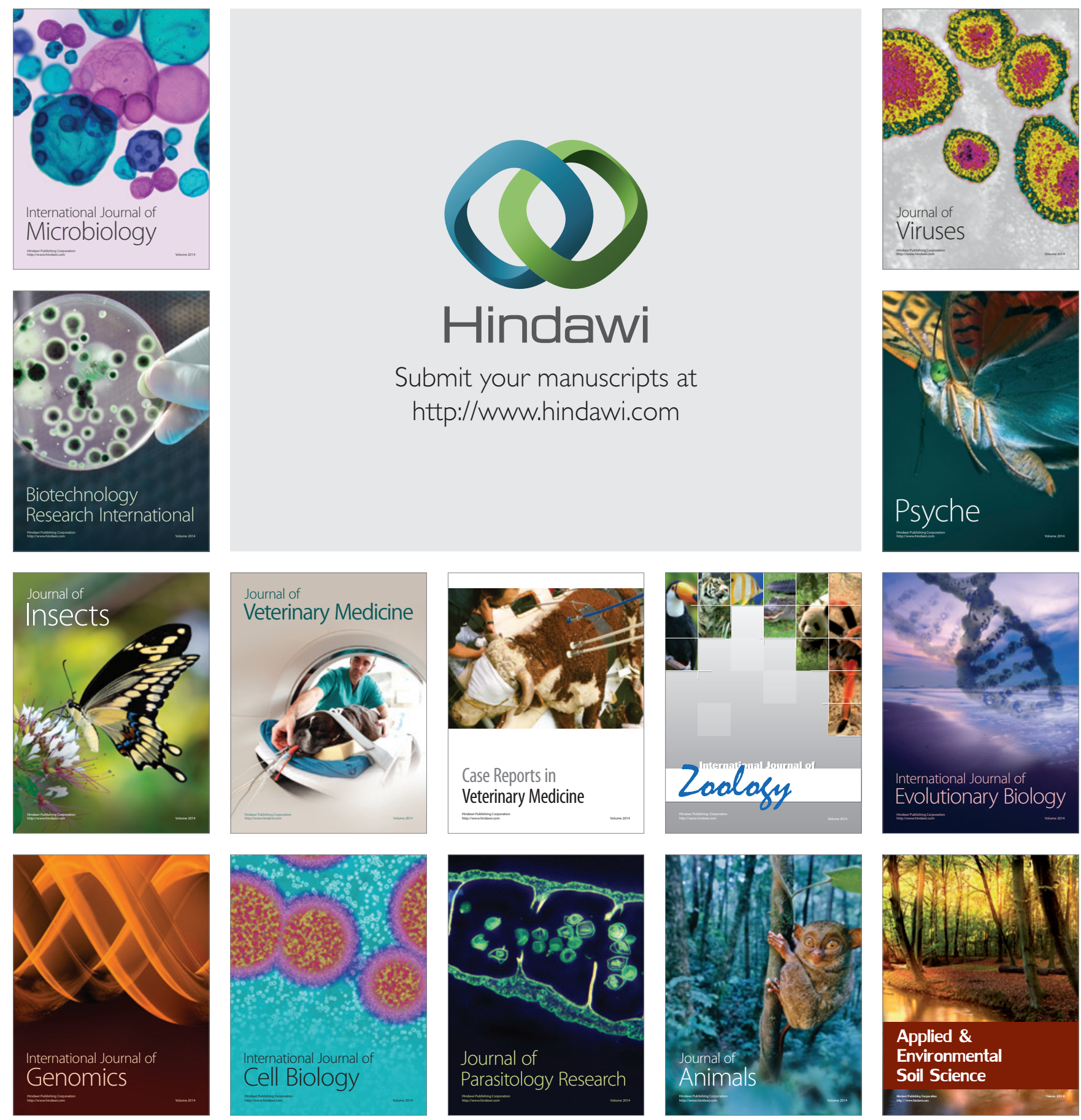